\title{
Learning from Real Life -- A Case Study of an Autistic Student in a Mainstream Secondary School Guo, Zhang
}

\author{
18J, Block 4, Harbour Place, 8 Oi King Street, Hung Hom, Hong Kong, China \\ Dylanzhang88@gmail.com or goria2018@163.com
}

Mobile: $15219432859 / 00852-53456962$

\begin{abstract}
Keywords: Autism Spectrum disorders (ASD), special education needs (SEN), instructional methods, English teaching.
\end{abstract}

\begin{abstract}
Based on the case of how a Secondary 2 student with autism spectrum disorders (ASD) adapted to the life in a mainstream secondary school, the author shares the application of Treatment and Education of Autistic and Communication handicapped Children (TEACCH) and effective ASD approved and effective intervention approaches and strategies in helping students with ASD adapt to the routine of school life.
\end{abstract}

\section{Scenario}

Harry is a Form 2 students in a mainstream secondary school (The case study follows his performance from Form 1 to Form 2). When the teacher extends the lesson longer, he will request the teacher dismiss the class immediately, then cry, scream and roll on the ground. Sometimes when the time displays on his watch is different from the time displayed on the class wall, he will repeatedly yell to the teacher that the time of the clock is incorrect. The essay will focus on the intervention approaches of addressing his misbehaviour when the lesson is extended and when there is a difference between the time displayed on his watch and the clock on the classroom wall.

Harry is diagnosed with ASD when he was 4 years old. He speaks good English and loves playing a certain game. He is interested in drawing trains. However, he does not how to communicate with others, for instance, he follows certain teachers and classmates. He does not know how to better control his emotions, as when he is furious, he will lie on the floor crying. He originates from a well-off family and he had SEN therapy courses during Form 1's the summer holiday.

Harry's case belongs to Tie- 3 case ${ }^{1}$. He is eligible for Individual Education Programme (IEP) ${ }^{2}$. His case is closely followed by the SEN Coordinator and SEN helpers as he is one of the most serious case in the school.

\section{Rationale}

The essay will base on Theory of Mind to analyse the deficits associated with autism and the behavioural consequences of the difficulties. Then intervention strategies based on Applied Behaviour Analysis (APA), Functional Assessment and TEACCH will be proposed.

1. The Hong Kong Education Bureau sets 3 tiers' support for SEN students. Tier-3 support refers to intensive individualized support for students with severe learning difficulties and. Tier-3 support refers to intensive individualized support for students with severe learning difficulties and SEN such as drawing up an Individual Education Plan.

2. IEP refers to Individual Education Plan, which is tailored-made to Tier-3 case.

\subsection{Theory of Mind}

Theory of mind (often abbreviated as ToM) is the ability to attribute mental states - beliefs, intents, desires, emotions, knowledge, etc. - to oneself, and to others, and to understand that others have beliefs, desires, intentions, and perspectives that are different from one's own. It is crucial for 
everyday social interactions and is used when analyzing, judging, and inferring others' behaviours. Deficits occur in people with autism spectrum disorders, clearly in Harry's case [1].

\subsection{Applied Behaviour Analysis (APA) \& Functional Assessment}

From Wikipedia, Applied behavior analysis (ABA) is a scientific discipline concerned with applying techniques based upon the principles of learning to change behavior of social significance. It is the applied form of behavior analysis; the other two forms are radical behaviorism (or the philosophy of the science) and the experimental analysis of behavior (or experimental research).

Based on APA and Functional Assessment, the author will analyze the Antecedent, Behavior and Consequence of the incident. [2]

\subsection{Treatment and Education of Autistic and Communication handicapped Children (TEACCH)}

According to Gary Mesibov, Professor and Director of Autism Independent UK, structured teaching is an important priority because of the TEACCH research and experience that structure fits the "culture of autism" more effectively than any other techniques we have observed. Organising the physical environment, developing schedules and work systems, making expectations clear and explicit, and using visual materials have been effective ways of developing skills and allowing people with autism to use these skills independently of direct adult prompting and cueing [3].

The author will explain in later how TEACCH is employed in helping Harry get rid of the dilemma.

\section{Analysis of the Problem}

In the scenario, Harry was troubled by two issues. One is the mismatch of the time displayed on his watch and on the classroom wall. The other is his insistence to strictly follow the class dismissal time. Due to the fact that Harry suffers from Autism, he has social challenges, communication difficulties and repetitive behaviours. From Autism Speaks [4], Harry have are the core autism symptoms.

Autism Speaks also mentions that 'unusual repetitive behaviors and/or a tendency to engage in a restricted range of activities are another core symptom of autism. Along these lines many children and adults with autism need and demand extreme consistency in their environment and daily routine. Slight changes can be extremely stressful and lead to outbursts.' [4]

In Harry case, he strictly sticks to the daily routine in school. When the class should have been dismissed, he feels anxious. Moreover, due to his lack of communication and social skills, he does not know how to express his anxiety and control his emotions. That is why outbursts of emotions will occur in the end.

For another, he is also stubborn. As when his watch shows the time when the class should be dismissed, he also requests the teacher to end the class and disturbs the class through screaming and rolling on the ground.

All his misbehaviour is related to the deficits of autism syndrome disorder.

Another aspect the author holds is that he is also weak in mind-read. He is unable to interpret that the teacher who extends the lessons for minutes just wants to finish the lesson and it will not cause big loss for the class.

\section{Intervention Approaches and Strategies}

After probing into the causes of the issue, the author proposes the following methods from several aspects, government level, school level and teacher level to address the problem. Each level interacts fundamentally with another. With concerned efforts and time, the problematic situation can be changed fundamentally. The intervention methods will be based on Positive Behaviour Support (PBS), including 3 stages, prevention, training and feedback. 


\subsection{Prevention Strategies (adjusting the contextual elements)}

\subsubsection{Poster to remind him to adjust his watch (Visualized Support, TEACCH))}

In Harry's case, we will adjust through contexts through two aspects to prevent the unfavourable situation. For one thing, a structured surrounding with visualized support to Harry should be established.

A poster on his desk should be pasted on his desk, reminding him to adjust the time on his watch with the classroom clock each morning when is back to school. He should follow the time displays on the classroom.

\subsubsection{Posters to remind him to keep quiet in the classroom (Visualized Support, TEACCH))}

Posters as reminders should be pasted on the class wall next to his desk to remind him to be quiet in the classroom.

\subsubsection{Forecast of a possible class extension}

At the beginning of each semester, there will be meeting on issues about students with special education needs (SEN Meeting) on Form level. The SEN Coordinator will inform all the Form teachers that a pre-notice should be provided for Harry if there is a foreseeable class extension, which will make Harry better prepared for a class extension.

4.1.4 Posters to show the relaxing techniques

Relaxing techniques can be displayed on the classroom. The details are shown in the training session. 4.1.5 'Embrace Change'--- New Year's Goal in IEP

Serving as an action plan, IEP should be effectively used. The SEN Coordinator sets the goal and theme of year for him in his IEP is to 'Embrace Change'. As a student with autistic syndrome disorder, he has difficulties in coping with trivial changes, however, setting the aim as accepting changes in IEP serves as an effective reminder and preventive measure.

Moreover, IEP is established collaboratively by different stakeholders, including Education Psychologist, SEN Coordinator, Class Teacher, Form Teachers and Parents. It is also clearly explained to Harry when it is established. When any misbehaviour related happens, IEP can serve as an effective reference and evidence.

\subsection{Training Strategies}

\subsubsection{Positive Reinforcement-Using Layers of Rewards \& Catering to His Interest}

Every day when he successfully adjusts his watch, he should get a tick mark on the checklist. The rewards will be layered--- weekly reward would be his sticker of his favourite cartoon character-Piper Pig and monthly reward would be an exercise book with his Piper Pig and a three-month reward would be an English comic book which is of his interest. The week, month and three months refer to consecutive 7 days, a month and 3 months. A reward will be provided as long as he can accomplish the task in a certain period of time. Therefore, even he fails to fulfil the task consequently, he still gets the chance to win the rewards.

\subsubsection{Displacement Behaviours}

If Harry fails to follow the instruction, some displacement behaviours can be employed. For example, he can read his English comics or draw some illustrations of his interest. Therefore, it is hoped that his attention can be averted to his interests other than the fact that the class time is extended.

\subsubsection{Relaxing Techniques}

The author suggests using Progressive Muscle Relaxation (PMR) [5] to relax. PMR is a technique that was developed by Doctor Edmund Jacobson as an easy to use stress reduction method. PMR is well suited for the classroom, and practicing the techniques can help to reduce performance or test related anxiety. Teachers can easily lead students through the exercises, and any student would benefit significantly from learning how to reduce their own physical and mental stress.

Firstly, PMR includes how to use proprioceptive sensory stimulation in the classroom. By including exercises in the classroom that provide proprioceptive stimulation, teachers can create a more inclusive classroom environment for students with ASD. 
Some proprioceptive activities can be utilised in Harry's case, like pulling or pushing items in the classroom, tidying up activities like sweeping, carrying heaving items and silly animals' walks, skipping, walking in slow motion and body stretching.

Secondly, Square breathing can be used. It is a ritual breathing technique that reduces anxiety and helps to visualize and separate the actions of deep breathing. Square breathing works extremely well in conjunction with PMR. [5]

\subsubsection{Isolation}

When there is an uncontrollable outburst of anger, the teacher should inform the Discipline Committee or SEN Committee to escort him to another room to calm down.

\subsubsection{Attending church services}

As the church provides a more tolerant and caring environment, some therapists proposed to let students suffer from autism spectrum disorders to join more activities in church and train their social and communication skills. Eric Schopler [6] wrote in Parent Survival Manual: A Guide to Crisis Resolution in Autism and Related Development that there is caring group in the church which focuses on providing support for ASD students.

$\mathrm{Ng}$ and Lam [7] also proposes that joining worships in church and socializing the church can also benefit students with autism spectrum disorder as Christians are comparatively more patient and caring.

\subsection{Feedback}

Two types of feedbacks will be provided. The visualized feedback and verbalized feedbacks.

\subsubsection{Visualized feedback}

Token systems will be used. Besides the layered rewards mentioned in training session, plastic beads will also be used to give the immediate feedback to Harry. With the red beads representing good behaviour and black unfavourable behaviour, Harry knows immediately what he should do and not do.

On regular lessons, the teacher will put a red bead in the cup if Harry perform well and a black one when he has misbehaviour. When other tokens are not ready, beads can be used to record his performance.

Moreover, setting specific aim in next year's IEP also serves as a visualized feedback. The aims which written in words serves as visualized prompts and feedbacks.

\subsubsection{Verbalized feedback \& Reframing}

An effective strategy the SEN Coordinator used in Harry's case was that he used examples related to his life to make it easier for Harry to understand.

He reframed the situation by saying 'sometimes the flight is delayed, will you stay and do not take the airplane if the flight is delayed?'

Harry got it immediately and said 'I will not'.

Then the teacher said, 'Then, why were you so furious when the lesson is delayed?'

In this way, Harry clearly understands his misbeviour and learns from the short but effective conversation.

\section{Conclusion}

In Harry's case, the problem was solved after the SEN Coordinator talked with him by explaining through the example of flight delay and some intervention methods were employed. In the real case, the problem is settled when training method d (isolation) and method e (attending church services) have not been used at all. But there are some misbehaved ASD students changed a lot after attending church services for around 1 year.

From the case, we can find that the teacher-student relationship also plays a significant role in setting the issue. Harry respects the authority--SEN Coordinator and trusts him and the solid relationship prompts his understanding and improvements. Also a benign cycle 'instructing, behaving and complimenting' [8] is formed. 
In conclusion, for students suffering from autistic syndrome disorder, learning from real life contexts is feasible and effective once strategic intervention approaches are adopted.

\section{References}

[1] Premack, David; Woodruff, Guy (December 1978). "Does the chimpanzee have a theory of mind?" Behavioral and Brain Sciences, special issue: Cognition and Consciousness in Nonhuman Species. Cambridge Journals. 1 (4): 515-526. doi:10.1017/S0140525X00076512

[2] Albert J. Kearney (2015). Understanding Applied Behavior Analysis: An Introduction to ABA for Parents, Teachers, and other Professionals. UK: Jessica Kingsley Publishers.

[3] Gary Mesibov. What is TEACCH? Retrieved from https://www.autismuk.com/training/what-is-teech/

[4] Autism Speaks. What Are the Symptoms of Autism? Retrieved from https://www.autismspeaks.org/what-autism/symptoms

[5] Teaching Students with Autism Spectrum Disorder: Relaxation Techniques for the Classroom. Retrieved from https://asdresources.wordpress.com/strategies/relaxation-techniques-for-the-classroom/

[6] Eric Schopler (1995). Parent Survival Manual: A Guide to Crisis Resolution in Autism and Related Developmental Disorders. North Carolina.1995 Kluwer Academic/Plenum Publishers.

[7] 吳麗端\&林嘉婷。《自閉症：兒童至成人的支援》。香港：基督教文藝。2015 年。

[8] 平岩幹男。來自星星的孩子: 泛自閉症障礙的療愈與對策. 台北, 台灣。書泉出版社。2012 年。 